\title{
Aleitamento Materno e os Educadores Infantis em Centros Municipais de Educação Infantil
}

Breastfeeding and Infant Teachers in Municipal Infant Education Centers

Lactancia Materna y Educadores Infantiles en los Centros Municipales de Educación Infantil

Elisangela Bellafronte ${ }^{1}$

Bianca da Silva Alcantara Pereira ${ }^{2}$

Ana Paula Contiero Torniato ${ }^{3}$

Andrea Ferreira Ouchi França ${ }^{4}$

Rosane Meire Munhak da Silva ${ }^{5}$

Adriana Zilly ${ }^{6}$

\section{Resumo}

Objetivo: Descrever o perfil dos educadores infantis e a infraestrutura dos Centros Municipais de Educação Infantil, também conhecidos como creches, relativos à promoção do aleitamento materno. Método: Trata-se de uma pesquisa descritiva transversal, no qual os participantes foram educadores infantis atuantes nos berçários I das creches do município de Foz do Iguaçu/PR e a coleta de dados ocorreu de abril a junho de 2015. Resultados: O perfil do profissional da sala de berçário I é predominantemente

${ }^{1}$ Bióloga. Doutora em Ciências pela UFSCar, Pós doutoranda do Programa de Pós Graduação em Ensino da UNIOESTE. E-mail: e_bio79@yahoo.com.br

${ }^{2}$ Enfermeira. Mestre em Ensino pela UNIOESTE, Doutoranda em Enfermagem em Saúde Pública pela Escola de Enfermagem de Ribeirão Preto da USP

${ }^{3}$ Enfermeira. Mestre em Ciências da Saúde pela UEM, Doutoranda em Enfermagem em Saúde Pública pela Escola de Enfermagem de Ribeirão Preto da USP

${ }^{4}$ Enfermeira Obstetra. Especialista em Unidade de Terapia Intensiva pela Faculdade de Enfermagem Luiza de Marilac, Doutoranda em Enfermagem em Saúde Pública pela Escola de Enfermagem de Ribeirão Preto da USP

${ }^{5}$ Enfermeira. Mestre em Biociência e Saúde pela UNIOESTE, Doutoranda em Enfermagem em Saúde Pública pela Escola de Enfermagem de Ribeirão Preto da USP

${ }^{6}$ Bióloga. Doutora em Ciências Biológicas pela UEM

Recebido: Nov/2017 - Aceito: Abr/2018.

Revist. Port.: Saúde e Sociedade. 2018;3(1):639-654. 
feminino, em idade superior a vinte e seis anos, com mais de seis anos de experiência, jornada de trabalho de 40 horas semanais, sem outros vínculos empregatícios e atuando como professor com mais de um ano de formação profissional. Ainda, possui filhos, amamentou por menos de seis meses, e mesmo tendo uma experiência positiva e sem problemas com aleitamento materno, afirmam sentir necessidade de educação continuada e capacitação profissional, especialmente em primeiros socorros. Sobre a infraestrutura das creches, todas as salas de berçário I possuíam lactário com estrutura mínima necessária, onde a maior parte das salas do município não possuía solário ou não têm incidência solar. Nenhuma instituição possui sala de amamentação, entrada livre para amamentação ou horário livre para amamentar e a maioria das salas contam com dois professores para quatorze alunos. Conclusão: Embora os educadores tenham experiência profissional e filhos, os mesmos não tem capacitação na temática e sentem a necessidade de tê-la. O local não foi considerado um bom lugar para amamentar. Incentivos em estrutura e capacitação destes profissionais são importantes, dada a magnitude do aleitamento materno.

\section{Descritores: Aleitamento Materno; Berçários; Educação Infantil;} Educação em Saúde.

\section{Abstract}

Objective: To describe the profile of infant educators and the infrastructure on Municipal Infant Education Centers, also known as nurseries, related to the promotion of breastfeeding. Method: Cross-sectional descriptive research, the participants were children's educators that work in Municipal Infant Education Centers, in Foz do Iguaçu / $P R$ and data collection occurred from April to June 2015. Results: The profile of the child's educator is predominantly female, over the age of twenty-six, with more than six years of experience, working 40 hours per week, with no other employment relationships. They have children, breastfed for less than six months, and despite having a positive experience and without problems with breastfeeding, they affirm that they need continued education and professional training, especially in first aid. Regarding the infrastructure, all centers had a minimum structure required, where most of the rooms in the municipality didn't have a solarium or have no solar 
incidence. No center has a nursing room, free entrance for breastfeeding or free time to breastfeed, and most rooms have two teachers for fourteen students. Conclusions: Although educators have professional experience and children, they don't have training in the subject and feel the need to have it. The place was not considered a good place to breastfeed. Incentives in the structure and training of these professionals are important due to the magnitude of breastfeeding.

\section{Descriptors: $\quad$ Breast $\quad$ Feeding;} Nurseries; Child Rearing; Health Education.

\section{Resumen}

Objetivo: Describir el perfil de los educadores infantiles y la infraestructura de los Centros Municipales de Educación Infantil, también conocidos como guarderías, relativos a la promoción de la lactancia materna. Metodo: Se trata de una investigación descriptiva transversal, en el cual los participantes fueron educadores infantiles actuantes en los viveros $I$ de las guarderías del municipio de Foz do Iguaçu/PR y la recolección de datos ocurrió de abril a junio de 2015. Resultados: El perfil del profesional de la sala de cuna de niños I es predominantemente femenino, en edad superior a veintiséis años, con más de seis años de experiencia, jornada de trabajo de 40 horas semanales, sin otros vínculos de trabajo y actuando como profesor con más de un año de formación profesional. Además, tiene hijos, amamantando por menos de seis meses, e incluso teniendo una experiencia positiva y sin problemas con la lactancia materna, afirman sentir necesidad de educación continuada y capacitación profesional, especialmente en los primeros auxilios. En cuanto a la infraestructura de las guarderías, todas las salas de cunas I poseían lactancia con estructura mínima necesaria, donde la mayor parte de las salas del municipio no poseía solarium o no tienen incidencia solar. Ninguna institución posee sala de lactancia, entrada libre para lactancia o horario libre para amamantar y la mayoría de las salas cuentan con dos profesores para catorce alumnos. Conclusiónes: Aunque los educadores tienen experiencia profesional e hijos, los mismos no tienen capacitación en la temática y sienten la necesidad de tener. El lugar no fue considerado un buen lugar para amamantar. Incentivos en estructura y capacitación de estos 
profesionales son importantes, dada la magnitud de la lactancia materna.

\section{Descriptores: Lactancia Materna;}

Casas Cuna; Crianza del Niño;

\section{Educación en Salud}

\section{Introdução}

A prática do aleitamento materno traz muitos benefícios para a saúde da mãe e para o desenvolvimento da criança $^{(1)}$. O leite materno, além de ser o mais completo alimento para o bebê, pode atuar como agente imunizador e tranquilizador para a criança. É operacionalmente simples, de baixo custo financeiro, auxilia na proteção contra câncer mamário e ovariano na mulher, auxilia na involução uterina, retarda a volta da fertilidade e aperfeiçoa a mulher em seu papel de mãe ${ }^{(2,3)}$. Apesar de pesquisas apontarem os benefícios e o crescimento de tal prática no Brasil, essa tendência ainda está muito aquém do esperado ${ }^{(4)}$

Quando a amamentação é realizada na primeira hora de vida, poderá diminuir os riscos de mortes neonatais, o que representa um indicador de excelência dessa prática ${ }^{(3)}$. Para tanto, estratégias vêm sendo desenvolvidas para incentivar e propiciar o aleitamento materno, como incentivos fiscais às empresas que adotam licença maternidade de 180 dias e hospitais e maternidades que adotam a Iniciativa Hospital Amigo da Criança. E é neste contexto que os Centros Municipais de Educação Infantil (CMEI's) devem ser considerados locais em que o aleitamento materno também precisa ser encorajado ${ }^{(2)}$.

Os Centros Municipais de Educação Infantil, também conhecidos como creches, foram uma importante conquista na educação infantil brasileira. Tais estabelecimentos tem proporcionado à criança de zero a cinco anos o direito a ter atendimento educacional, o que reforçou as ações em torno da proposta educativa das instituições, antes restrita a uma pequena parcela da população que tinha acesso a jardins de infância e instituições equivalentes de educação infantil $^{(5)}$.

De acordo com a Lei de Diretrizes e Bases da Educação (LDB), a prioridade das creches é o atendimento em educação infantil, trabalhando o desenvolvimento intelectual e o acesso ao saber, bem como o direito à socialização, às vivências infantis e aos cuidados assistenciais específicos e necessários ${ }^{(6)}$. As creches também vêm compartilhando uma responsabilidade 
que antes era uma atribuição de responsabilidade da família, a alimentação, entretanto é essencial que pais, responsáveis e educadores estejam envolvidos no processo de construção de hábitos alimentares saudáveis no ambiente escolar e intervenham positivamente sobre as práticas alimentares das crianças $^{(7)}$. Nesse sentido, autores referem que, o processo de educar é amplo, não se resume a passar conteúdos teóricos e práticos, pois contribui para o desenvolvimento da criança integralmente ${ }^{(8)}$.

Os educadores infantis devem promover saúde, orientar e incentivar as mães na manutenção do aleitamento materno, uma vez que, muitas crianças frequentam as creches antes do primeiro ano de vida, momento em que o leite materno deveria ser o único alimento até os seis meses de idade, e complementar após este período ${ }^{(2)}$. Desta forma, uma portaria do Ministério da Saúde, no 321 de 1988 foi criada com o objetivo de garantir a prática da amamentação através de salas destinadas à recepção das mães que necessitam amamentar seus filhos que se encontram sob a proteção e cuidados da creche, devendo contar com equipamento apropriado. Quanto a sua infraestrutura, a área das salas devem possuir $1,20 \mathrm{~m}^{2}$ por criança em fase de amamentação e deve ser capaz de atender $30 \%$ do total de crianças de 3 meses a um ano. A sala também deve ser dotada de lavatório, localizada na unidade de administração objetivando facilitar o acesso às mães que vêm de fora e não alterando o movimento normal dos trabalhos com as demais crianças $^{(9)}$.

Desta forma, o objetivo do presente estudo foi descrever o perfil dos educadores infantis e a infraestrutura dos Centros Municipais de Educação Infantil, relativos à promoção do aleitamento materno.

\section{Método}

Foi realizado um estudo descritivo transversal como estratégia metodológica. O município de Foz do Iguaçu, cenário deste estudo, está localizado no oeste do estado do Paraná e conta atualmente com 33 Centros Municipais de Educação Infantil, sendo que, 15 possuem turmas de berçário I que atendem crianças de seis meses a um ano. Durante a coleta de dados, quatro destes centros estavam com seus berçários fechados por falta de profissionais ou problemas estruturais. Portanto, o presente estudo foi realizado em 11 Centros Municipais de Educação 
Infantil, distribuídos por cinco Distritos

Sanitários (Quadro 1).

\section{Quadro 1 - Distribuição dos Centros Municipais de Educação Infantil com Berçário I por Distrito Sanitário}

\begin{tabular}{cccc}
\hline Centros Municipais de & Bairro & Distrito & Situação \\
Educação Infantil & Sanitário & \\
\hline Três Lagoas & Três Lagoas & Nordeste & Fechado \\
Amor Perfeito & Cidade Nova & Norte & Aberto \\
Dom Olivio Fazza & Porto belo & Norte & Aberto \\
Flor de Lis & Vila C Nova & Norte & Aberto \\
José Bento Vidal & Vila C Velha & Norte & Aberto \\
Prof Nilva de Jesus & Jardim Karla & Norte & Aberto \\
Bárbara Januário Matos & Morumbi II & Leste & Aberto \\
Maricota Basso & Jardim São Paulo II & Leste & Aberto \\
São Francisco & Morumbi II & Leste & Aberto \\
Novo Horizonte & Jardim Novo Horizonte & Sul & Fechado \\
Soldadinho de Chumbo & Profilurb I & Sul & Fechado \\
Ozíres dos Santos & Profilurb I & Sul & Aberto \\
Ariano Suassuna & Porto Meira & Sul & Aberto \\
Moraci F. Venson & Vila Boa Esperança & Oeste & Fechado \\
Victorio Basso & Parque Imperatriz & Oeste & Aberto \\
\hline
\end{tabular}

Fonte: Prefeitura Municipal de Foz do Iguaçu (PMFI), 2015.

De acordo com a Secretaria de Educação do Município de Foz do Iguaçu e a Deliberação $n^{0}$ 02/14, em cada turma do berçário I de cada Centro Municipal de Educação Infantil deveriam estar atuando dois profissionais da educação, totalizando 22 educadores.

O critério de inclusão para a pesquisa foi aceitar participar e estar atuando no mínimo há seis meses na profissão. Conforme Lefèvre; Lefèvre $^{(10)}$, a opção de entrevistar todos os participantes da pesquisa ocorreu pelo pré-conhecimento das características do universo a ser pesquisado, pela facilidade de acesso aos participantes a serem entrevistados e por se tratar de um universo consideravelmente pequeno.

A coleta de dados ocorreu entre abril e junho de 2015, nas dependências 
dos Centros Municipais de Ensino Infantil com os educadores infantis, por meio de agendamento prévio via telefone, com duração de 20 minutos. $\mathrm{O}$ questionário semiestruturado foi avaliado previamente por dois profissionais especialistas na área da enfermagem e educação, e estava organizado com perguntas sobre aspectos sóciodemográficos do educador (idade, formação, função, se possui filhos, número de filhos), características relacionadas ao aleitamento materno (tempo de amamentação e experiência com a amamentação) e sobre as condições estruturais dos Centros Municipais de Educação Infantil visitados.

Considerando os aspectos éticos, o conteúdo do Termo de Consentimento Livre e Esclarecido foi lido, explicitando os objetivos do estudo, garantindo sigilo ao entrevistado e liberdade para não participação. Este estudo foi aprovado pelo Comitê de Ética em Pesquisa da Universidade Estadual do Oeste do Paraná, sob parecer número 931.596.
A análise de dados foi realizada por estatística descritiva, a partir do cálculo de frequências absolutas e relativas.

\section{Resultados}

A amostra foi composta por 19 educadores infantis, distribuídos em 11 Centros Municipais de Educação Infantil.

A tabela 1 apresenta dados que caracterizam o perfil da população nas unidades pesquisadas. A caracterização dos participantes deste estudo aponta para uma totalidade feminina $(100 \%)$ e chama a atenção para a experiência pessoal dessas educadoras, pois $40 \%$ delas não praticaram $\mathrm{o}$ aleitamento materno até o sexto mês de vida de seus filhos. 
Tabela 1 - Caracterização dos Educadores de Berçário I nos Centros Municipais de Educação Infantil

\begin{tabular}{|c|c|c|c|c|c|}
\hline Variáveis & $\mathrm{N}$ & $\%$ & Variáveis & $\mathrm{N}$ & $\%$ \\
\hline & & & Possui filhos & & \\
\hline & & & Nenhum & 05 & 26 \\
\hline & & & Um filho & 06 & 32 \\
\hline & & & Dois filhos & 05 & 26 \\
\hline Idade & & & Três filhos & 03 & 16 \\
\hline Até 25 anos & 03 & 16 & & & \\
\hline 26-30 anos & 05 & 26 & Amamentou & & \\
\hline $31-35$ anos & 02 & 11 & Menos de 6 meses & 06 & 40 \\
\hline $36-40$ & 02 & 11 & Entre 6-12 meses & 05 & 36 \\
\hline $41-45$ anos & 01 & 05 & Mais de 12 meses & 03 & 24 \\
\hline Acima de 46 anos & 06 & 32 & & & \\
\hline $\begin{array}{l}\text { Tempo no local de } \\
\text { trabalho }\end{array}$ & & & $\begin{array}{l}\text { Experiência com AM } \\
\text { Positiva, mas tive } \\
\text { problemas }\end{array}$ & 05 & 36 \\
\hline Até 1 ano & 02 & 11 & Positiva, sem problemas & 08 & 57 \\
\hline $1-5$ anos & 08 & 42 & Não teve a experiência & 01 & 07 \\
\hline $6-10$ anos & 03 & 15 & & & \\
\hline Acima de 10 anos & 06 & 32 & $\begin{array}{l}\text { Formação em AM } \\
\text { Não }\end{array}$ & 17 & 89 \\
\hline Função & & & $\operatorname{Sim}$ & 02 & 11 \\
\hline Professor & 17 & 89 & & & \\
\hline Auxiliar de ensino & 02 & 11 & $\begin{array}{l}\text { Educação continuada } \\
\text { Não }\end{array}$ & 17 & 89 \\
\hline Pós-graduação na área & & & $\operatorname{Sim}$ & 02 & 11 \\
\hline $\operatorname{Sim}$ & 14 & 74 & & & \\
\hline Não & 05 & 26 & $\begin{array}{l}\text { Necessidade de } \\
\text { capacitação profissional }\end{array}$ & & \\
\hline Tempo de formação & & & Sim & 18 & 95 \\
\hline Até 1 ano & 05 & 26 & Não & 01 & 05 \\
\hline $1-5$ anos & 10 & 53 & & & \\
\hline $6-10$ anos & 03 & 16 & & & \\
\hline Acima de 10 anos & 01 & 05 & & & \\
\hline
\end{tabular}

Referente à estrutura que atende ao berçário I, todas as creches contavam com o lactário exclusivo, geladeira, fogão e pia. Entretanto, nenhuma unidade possuía sala de amamentação, e a maioria não havia solário, nem entrada livre para amamentação, nem um horário exclusivo para esta prática (Tabela 2). 
Tabela 2 - Dados sobre Estrutura do Berçário I nos Centros Municipais de Educação Infantil

\begin{tabular}{lll}
\hline Variáveis & N & $\%$ \\
\hline Possui micro-ondas & & \\
Sim & 09 & 82 \\
Não & 02 & 18 \\
& & \\
Solário & 05 & 46 \\
Não & 02 & 18 \\
Sim & 03 & 27 \\
Sim, mas não bate sol & 01 & 09 \\
Sim, compartilhado & & \\
Entrada livre para & & \\
amamentação & 08 & 73 \\
Não & 03 & 27 \\
Sim & & \\
Horário para & & \\
amamentação & 08 & 73 \\
Não & 01 & 09 \\
Sim, qualquer horário & 02 & 18 \\
Sim, horário do leite & & \\
Profissionais por turma de & & \\
berçário com 14 alunos & & \\
Dois educadores por & 08 & 73 \\
turma & & \\
Um educador por turma & 03 & 27 \\
\hline
\end{tabular}

\section{Discussão}

A totalidade dos educadores no presente estudo é do sexo feminino. A feminização da docência não é um evento recente. É importante lembrar que se trata de um dos primeiros campos de trabalho para mulheres das chamadas classes médias, estudiosas e portadoras de uma feminilidade idealizada para essa classe. Além disso, são também protagonistas da luta pelo alargamento da participação feminina na esfera econômica ${ }^{(11)}$. Naylander et al. ${ }^{(12)}$, em estudo sobre o perfil dos educadores infantis, registraram que todas eram do sexo feminino. Educadora infantil continua sendo a expressão mais utilizada na literatura para tratar da respectiva profissão, que 
tende a buscar as experiências de cuidado infantil na sua trajetória familiar como inspiração para a atuação profissional, o que vai de encontro com os nossos achados.

$\mathrm{Na}$ pesquisa, a idade predominante foi acima dos 30 anos de idade, com mais de $50 \%$ das educadoras nesta faixa etária (Tabela 1). Um estudo sobre características e problemas na formação dos professores da Educação Infantil encontrou um perfil semelhante, onde a faixa etária dos alunos do curso de Pedagogia se diferenciava das demais licenciaturas: $35 \%$ dos alunos estavam na faixa etária ideal entre $18 \mathrm{e}$ 24 anos e a maioria (65\%) apresentava uma idade superior, o que indica uma tendência nesta área ${ }^{(13)}$.

Dentre as entrevistadas, quase 90\% são professores (Tabela 1). O pequeno percentual restante representa o auxiliar de ensino, que tem entre seis meses e um ano, ainda dentro do estágio probatório do concurso público, observando-se que, posteriormente, esse período progride para o cargo de professor. Oliveira e Côco ${ }^{(14)}$ alerta com base em estudos recentes a desvalorização evidenciada pelo quadro de profissionais auxiliares no magistério, uma vez que, oferta uma remuneração menor por carga horária de trabalho igual aos demais profissionais, além de relacionar-se com a oferta do cuidado com crianças, hierarquizando os eixos da educação: o cuidar e o ensinar.

O Plano Nacional de Educação (PNE) vigente de 2014 estabelece diretrizes, metas e estratégias de concretização no campo da educação, de modo que os planos dos municípios devem ser consonantes com o PNE. Dentre suas metas está a pós-graduação dos professores da Educação Básica que, em 2014, tinha $31,1 \%$ dos profissionais especialistas, estabelecendo a meta de $50 \%$ até $2024^{(15)}$. Os professores da Educação Infantil nos Centros Municipais de Educação Infantil de Foz do Iguaçu já superaram a meta do PNE, pois, mesmo a maioria desses profissionais tendo entre 1 a 5 anos de atuação, já possuem qualificação e interesse em estar buscando especialização na área.

Sobre a maternidade, $74 \%$ das profissionais são mães (Tabela 1). Por muito tempo, a mulher não era comprometida com a esfera profissional, a imagem feminina era relacionada às funções de mãe e esposa, sempre afastada de suas realizações profissionais $^{(16)}$. No entanto, atualmente, adiar a maternidade é comum, a prole numerosa e a necessidade de passar pela experiência 
da maternidade perderam $\mathrm{o}$ foco $\mathrm{e}$ dominância, passando a ser uma escolha, na medida em que perde o caráter obrigatório moral imposto pela sociedade.

Quanto às práticas de amamentação, dificuldades devem ter sido enfrentadas pelas educadoras entrevistadas, visto que cerca de $40 \%$ das que são mães amamentaram seus filhos por menos de seis meses de vida, inferior ao recomendado ${ }^{(17)}$. Estes dados refletem a existência de obstáculos que precisam ser superados pelas mães que desmamaram precocemente. Estes, em sua maioria, são enraizados na cultura dominante do determinismo biológico do aleitamento materno e que precisam ser dialogados com as progenitoras e com a sociedade e não só julgados e condenados. A necessidade de protrusão do mamilo; o conformismo com a dor na amamentação; o não cumprimento das leis trabalhistas em favorecimento ao aleitamento materno pelas empresas e a credibilidade em mitos do leite materno podem ser alguns destes obstáculos que precisam ser revistos e aprofundados $^{(18)}$.

A maioria destes profissionais não teve em sua formação nenhuma abordagem sobre o aleitamento materno (Tabela 2), o que de fato se confirma no documento intitulado "Orientações
Curriculares para o Curso de Formação de Docentes da Educação Infantil e Anos Iniciais do Ensino Fundamental, em Nível Médio, na Modalidade Normal", no qual não existe menção nem mesmo à alimentação infantil ${ }^{(19)}$.

$$
\text { Quase 90\% dos profissionais }
$$
afirmam que, na gestão atual, não havia educação continuada (Tabela 1). Aquelas que afirmaram ter, na verdade se referem ao curso de primeiros socorros de iniciativa do curso de Enfermagem da Universidade Estadual do Oeste do Paraná, no campus de Foz do Iguaçu, em parceria com a Secretaria de Educação, isso demostra que é preciso avançar nas iniciativas em promover seus educadores.

Logo depois de sua formação básica, os professores enfrentam práticas sem se sentirem preparados para os problemas decorrentes da atividade diária, portanto, a necessidade de ser capacitado ${ }^{(19)}$. Segundo as novas Diretrizes Curriculares Nacionais, a formação continuada compreende dimensões coletivas, organizacionais e profissionais, bem como o repensar do processo pedagógico, dos saberes e valores, e envolve atividades de extensão, grupos de estudos, reuniões pedagógicas, cursos, programas e ações para além da formação mínima exigida ao exercício do magistério na educação 
básica, tendo como principal finalidade a reflexão sobre a prática educacional e a busca de aperfeiçoamento técnico, pedagógico, ético e político do profissional docente ${ }^{(21)}$. Desta forma, a formação continuada, mais que uma exigência, é um direito do docente que lhe favorece a valorização profissional.

Nestas perspectivas, compreende o atual no cenário brasileiro, em que se verifica a baixa prevalência do aleitamento materno entre crianças que frequentam os Centros Municipais de Educação Infantil. No momento em que as mães necessitam deixar seus filhos para trabalharem, estas recebem pouco apoio para manter o aleitamento materno exclusivo, tendo assim o início precoce da introdução de outros alimentos. Cabe ressaltar que, tal preocupação materna para esta atitude envolve a segurança de que a criança terá uma boa aceitação de outros alimentos, assim como, uma boa adaptação neste ambiente, uma vez que, a criança permanecerá grande parte do tempo. Deste modo, se fazem necessárias ações para fortalecer as práticas do aleitamento materno nos Centros Municipais de Educação Infantil, compreendendo estes espaços como locais capazes de apoiar, manter expectativas positivas, ouvir e potencializar a educação materna sobre os benefícios e a manutenção do aleitamento materno ${ }^{(2)}$.

Quanto à infraestrutura, algumas inconformidades foram encontradas nos Centros Municipais de Educação Infantil de Foz do Iguaçu, como falta de espaço para amamentação e solário. A sala de amamentação é uma facilidade para a prática do aleitamento materno. Esta facilidade deve ser transmitida através de condições estruturais e rotinas de acolhimento. Entretanto, apesar de ser uma facilidade, não é decisiva para o sucesso da prática especialmente porque a instituição precisa deixar a mãe à vontade sem constrangimentos, amparada sem que se sinta invadindo o espaço alheio. E ainda, há de superar alguns desafios para implantação das salas de amamentação, tais como, problemas financeiros, físicos, estruturais e culturas, assim como a consciência social da importância da amamentação para o desenvolvimento na primeira infância ${ }^{(22)}$.

No berçário, o solário é um ambiente onde as crianças iniciam a prática da socialização. As experiências do solário são intencionais e é um rico momento de observação e intervenção educacional das professoras, pois nestes espaços ocorrem os conflitos por disputas de brinquedos ou de atenção. 
Por ser espaço de movimento é fundamental que essas experiências tenham por objetivo a motricidade ${ }^{(23)}$.

Nas 11 salas de berçário I, esperava-se encontrar vinte e dois profissionais, conforme descrito no próprio documento informado pelo município, com base na Deliberação ${ }^{\circ}$ $02 / 14^{(24)}$. Na realidade, as salas não atendiam à Resolução e, por essa razão, o número de entrevistados foi inferior ao previsto por Lei: em oito salas de berçário I haviam dois professores e em três salas de berçário I apenas um professor, sendo que a proporção adequada é de um professor a cada seis alunos.

Para Pandini-Simiano ${ }^{(25)}$, o espaço (projetado, planejado) não garante a acolhida, o desafio, a exploração, a participação e expressão de crianças e adultos que partilham e comungam o mesmo espaço. $\mathrm{O}$ espaço pode agradar aos olhos dos adultos, mas muitas vezes, pode carecer da personalidade dos bebês que o habitam. Há instituições que parecem limpas, ávidas e com estruturas modernas, porém sente-se falta de marcas pessoais, simbólicas e singulares do grupo que por elas é habitado. Segundo o mesmo autor, as crianças têm direito a um espaço físico adequado e de qualidade.

\section{Conclusão}

A experiência pessoal positiva das educadoras com o aleitamento materno não foi suficiente ou motivadora para incentivá-las a promover a continuidade em amamentar. A expectativa de mudança desta prática é aproveitar a necessidade de educação continuada $\mathrm{e}$ capacitação profissional. Não se trata de um capricho afetivo, mas de uma prática comprovadamente eficaz na redução da morbimortalidade infantil e, mais do que isso, oferece à criança uma expectativa de saúde na vida adulta, muito importante quando se trata de crianças que vivem em condições socioeconômicas menos favorecidas.

Os berçários que atendem o município têm uma estrutura que, em grande parte, atendem às normas para a instituição, porém deixou a desejar nos solários que não têm incidência solar, na falta de salas de amamentação e no número de professores por aluno, o que demonstra irregularidades nestes estabelecimentos. Importante pontuar que a sala de amamentação como estratégia isolada não deve ser motivadora para amamentação numa instituição, é preciso que a instituição encoraje e acolha a mãe e seu lactente. 


\section{Referências}

1. Vasquez J, Dumith SC, Susin LRO. Aleitamento materno: estudo comparativo sobre o conhecimento e o manejo dos profissionais da Estratégia Saúde da Família e do Modelo Tradicional. Saúde Materno Infantil (Recife) [periódico na internet]. 2015 [citado 2017 out. 20]; 15(2):181-92. Disponível em: http://www.sciel o.br/pdf/rbsmi/v15n2/1519-3829-rbsmi15-02-0181.pdf.

2. Souza MHN, Sodré VRD, Silva FNF. Prevalência e fatores associados à prática da amamentação de criança que frequentam uma creche comunitária. Enfermagem (Concepcion) [periódico na internet]. 2015 [citado 2017 out. 25]; 21(1):55-67. Disponível em: https://scie lo.conicyt.cl/pdf/cienf/v21n1/art_06.pdf

3. Netto A, Spohr FA, Zilly A, França, AFO, Rocha-Brischiliari SC, Silva RMM. Breastfeeding in the first hour of life at an institution with the Baby-Friendly Hospital initiative. Cienc. Cuid. Saude. 2016; 15(3): 51521.

4. Nunes, LM. Importância do aleitamento materno na atualidade. Pediatria (Rio Grande do Sul) [periódico na internet]. 2015 [citado 2017 out. 28]; 4(3): 55-8. Disponível em: http:/www.sprs.com.br/sprs2013/ bancoimg/160529234034bcped_v4_n3_ a2.pdf.

5. Fernandes, FS, Domingues, JR. Early childhood education in São Paulo state: conditions of care and profile of children. Educação e Pesquisa (São Paulo) [periódico na internet]. 2017 [citado 2017 nov. 5]; 43(1): 145-60. Disponível em: http://www.scielo.br/ scielo.php?pid $=\mathrm{S} 1517-9702201700010$ 0145\&script $=$ sci_arttext\&tlng $=\mathrm{em}$.
6. Rodrigues $\mathrm{BC}$, D'Artibale EF, Barbieri MC, Bercini LO, Higarashi IH. Intersecções do cuidado à saúde nos centros de educação infantil: percepção das mães. Enfermagem (Rio de Janeiro) [periódico na internet]. 2014 [citado 2017 nov. 8]; 22(1): 71-6. Disponível em: http://www.scielo.br/scielo.php?pid $=\mathrm{S} 1517-97022017000100145 \&$ script $=\mathrm{s}$ ci_arttext\&tlng=em.

7. Cavalcanti, CL, Lima LG, Neves AFGB, Aquino JS. Educação nutricional em creches no município de Patos - PB. In: One, GMC, Albuquerque HN, organizadores. Saúde e Meio Ambiente: os desafios da interdisciplinariedade nos ciclos da vida humana. Campina Grande: Instituto Bioeducação; 2017: 101-17.

8. Ramos DD, Salomão NMR. Desenvolvimento infantil: concepções e práticas de educadoras em creches públicas. Teoria e Prática (São Paulo) [periódico na internet]. 2013 [citado 2017 nov. 12]; 15(3): 200-13. Disponível em: http://pepsic.bvsalud.or $\mathrm{g} /$ scielo.php? script $=$ sci_arttext\&pid $=\mathrm{S} 1$ 516-36872013000300015.

9. Ministério da Saúde (BR). Portaria $n^{\circ} 321$, de 26 de maio de 1988. Brasília: Ministério da Saúde; 1988.

10. Lefèvre F, Lefèvre AMC. O discurso do sujeito coletivo: um novo enfoque em pesquisa qualitativa (desdobramentos). Caxias do Sul: EDUSC; 2005.

11. Vianna CP. A feminização do magistério na educação básica e os desafios para a prática e a identidade coletiva docente. In: Yannoulas SC, organizador. Trabalhadoras: análise da feminização das profissões e ocupações. Brasília: Abaré; 2013; 159-80. 
12. Nylander PIA, Santos RCB, Magalhães LS; Afonso T, Cavalcante LIC. Educadores infantis: aspectos da formação profissional e do trabalho em creche. Psicologia (Ribeirão Preto) [periódico na internet]. 2012 [citado 2017 nov. 14]; 20(2): 666-77. Disponível em: http://webcache.googleu sercontent.com/search?q=cache:KRVQ1 RsA1HcJ:pepsic.bvsalud.org/scielo.php \%3Fscript\%3Dsci_arttext $\% 26$ pid\%3DS 1413-389X2012000200021+\&cd=1\&hl $=$ pt-BR\&ct $=$ clnk $\& \mathrm{gl}=$ br.

13. Gatti B. A. Formação de professores no Brasil: características e problemas. Educação e Sociedade (Campinas) [periódico na internet]. 2010 [citado 2017 nov. 19];31(113): 1355-79. Disponível em: http://www. scielo.br/pdf/es/v31n113/16.pdf.

14. Oliveira CRP, Côco V. Early Childhood Education: Formative Processes, Practices and the Configuration of Teaching in the Municipal Schools of Early Childhood and Elementary Education of Guarapari/ES. Education (New York) [periódico na internet]. 2014 [citado 2017 nov. 26]; 4(8): 614-22. Disponível em: http://www.academicstar.us/Upload File/Picture/2015-1/201512042115161. pdf.

15. Ministério da Educação (BR). Plano Nacional de Educação (PNE). Lei $\mathrm{n}^{\circ}$ 13.005, de 25 de junho de 2014. Brasília: Ministério da Educação; 2014.

16. Pedroso RMCJ, Galvão DMG, C Galvão, Castro FV. Amamentação em mulheres trabalhadoras e alunas do ensino superior público de Coimbra. IJODAEP. 2014; 1(2): 419-24.

17. Ministério da Saúde (BR). Secretaria de Atenção à Saúde. Departamento de Atenção Básica. Saúde da Criança: crescimento e desenvolvimento. Brasília: Ministério da Saúde; 2012.
18. Prado CVC, Fabbro MRC, Ferreira GI. Desmame precoce na perspectiva de puérperas: uma abordagem dialógica. Enfermagem (Florianópolis) [periódico da internet]. 2016 [citado 2017 set 05]; 25(2): 1-9. Disponível em: http://www. redalyc.org/articulo.oa? $\mathrm{id}=7144625900$ 6.

19. Secretaria de Estado da Educação (PR). Superintendência da Educação. Departamento de Educação e Trabalho. Orientações Curriculares para o Curso de Formação de Docentes da Educação Infantil e Anos Iniciais do Ensino Fundamental, em Nível Médio, na Modalidade Normal. Curitiba : SEED PR; 2014.

20. Correia ML. A formação inicial do professor: os desafios e tensões que a prática pedagógica impõe. (Paraná) [periódico na internet]. 2012 [citado 2017 dez. 2]; 9(2): 11-0. Disponível em: https://revistas.unicentro.br/index.php/a nalecta/article/viewFile/1717/1546.

21. Dourado LF. Diretrizes curriculares nacionais para a formação inicial $\mathrm{e}$ continuada dos profissionais do magistério da educação básica: concepções e desafios. Educação e Sociedade (São Paulo) [periódico na internet]. 2015 [citado 2017 dez. 4]; 36(131): 299-24. Disponível em: http://www.scielo.br/scielo.php?pid=S0 101-73302015000200299\&script $=$ sci_a bstract\&tlng $=$ pt.

22. Fernandes VMB, Santos EKA, Erdmann AL, Pires DEP, Zampieri MFM, Gregório VRP. Implantação de salas de apoio à amamentação em empresas públicas e privadas: potencialidades e dificuldades. Enfermagem (Rio Grande do Sul) [periódico na internet]. 2016 [citado 2017 dez. 7]; 37: 1-9. Disponível em: http://www.scielo.br/scielo.php?pid=S1 983-14472016000500419\&script $=$ sci_a bstract\&tlng $=$ pt. 
23. Malvezzia RAB, Stranga BLS. O Trabalho com Bebês: uma Reflexão Sobre Ambientação e Espaços no Berçário. Ciências Humanas (Paraná) [periódico na internet]. 2015 [citado 2017 dez. 21]; 16(4): 296-03. Disponível em: http://www.pgsskroton .com.br/seer/index.php/ensino/article/vi ew/3281/2948.

24. Conselho Estadual de Educação (PR). Deliberação $\mathrm{n}^{\mathrm{o}}$ 02, de 3 de dezembro de 2014. Normas e princípios para Educação Infantil no Sistema de Ensino do Estado do Paraná. Curitiba: CEE PR; 2014.

25. Pandini-Simiano L. A organização dos espaços como elemento curricular na creche: formas silenciosas de educar e cuidar. Nuances: estudos sobre Educação (São Paulo) [periódico na internet]. 2016 [citado 2017 dez. 22]; 27(3): 43-57. Disponível em: http://revista.fct.unesp.br/index.php/Nua nces/article/download/4578/3657. 